Article

\title{
Formation of Coatings Based on Titanium Dioxide Nanosolson Polyester Fibre Materials
}

\author{
Natalia Prorokova ${ }^{1,2, *}$, Tatiana Kumeeva ${ }^{1}$ and Igor Kholodkov ${ }^{1,3}$ \\ 1 G.A. Krestov Institute of Solution Chemistry of the Russian Academy of Sciences, Akademicheskaya St., 1 , \\ 153045 Ivanovo, Russia; tyk@isc-ras.ru (T.K.); kholodkov@isuct.ru (I.K.) \\ 2 Department of technology of electronic materials and devices, Ivanovo State Polytechnic University, \\ Sheremetevsky Ave., 21, 153000 Ivanovo, Russia \\ 3 Ivanovo State University of Chemistry and Technology, Sheremetevsky Ave., 7, 153000 Ivanovo, Russia \\ * Correspondence: npp@isc-ras.ru
}

Received: 26 December 2019; Accepted: 16 January 2020; Published: 19 January 2020

check for updates

\begin{abstract}
In this paper, we show that functionalization of fibrous materials through coating formation is hindered by the need to preserve the capillary-porous system of the fabric and its drapability. Additionally, such coatings must be resistant to abrasion and washing. We consider ways of solving these problems by analysing the formation of a stable coating based on photoactive titanium dioxide on a polyester fibre material as an example. The purpose of such coatings is to destroy coloured organic contaminants when the fabric is exposed to sunlight. We show that a polyester fabric with a titanium dioxide coating can become highly photochemically active and capable of inhibiting the vital activity of gram-negative bacteria and remaining soft and breathable at the same time. We also determined that depositing a titanium dioxide coating does not reduce the polyester fabric tensile strength. Polyester fabrics with photoactive properties can be widely used as decorative and trimming materials-for housing decoration, production of curtains and other decorative interior design elements.
\end{abstract}

Keywords: coatings; polyester fabric; nanosols; titanium dioxide; photoactivity; antibacterial properties

\section{Introduction}

The problem of modifying fibrous materials in order to endow them with fundamentally new properties is of relevance, as attempts are now being made to create "smart" textiles and "smart" clothes, i.e., materials and clothes that respond to external effects. Researchers have recently been paying increasing attention to the use of the sol-gel technology of nanosol synthesis in the processes of fibrous material modification and the formation of a modifying coating on the fibres. The implementation of this technology implies that a small amount of the modifying compound is used, and the fabric is treated at rather low temperatures usingtraditional equipment [1-6].

Nanosols represent colloidal solutions of particles of nano-sized inorganic oxides in aqueous or organic solvents [1,2]. A very large surface area of such particles makes nanosols metastable [7]. That is why they easily form coatings when the solvent is removed. The coatings can range from monomolecular films to three-dimensional objects several hundred nanometers thick. The process of coating formation includes the stages of nanoparticle synthesis involving a sol-gel process [8,9], particle deposition, and drying [1,3].

The last few years have seen the publication of a lot of papers devoted to the problem of endowing fibre materials with new properties through the use of nanosols. However, the results of a whole range of studies are incorrect because the authors in many cases did not take into account the features of the 
tissues as modification objects when forming coatings. In particular, they did not takeinto account the requirement of preserving the softness, drapability, breathability and some other properties (inherent in textile fabrics) by fibrous materials. Additionally, such coatings must be resistant to severe exposure a fibrous material is subjected to when used. The coatings must retain their properties after repeated washing and/or dry cleaning. This fact is also emphasized by the authors of review [10] on textiles with special wettability.

In this work, we propose a solution to the problem of modification of a polyester fabric without deterioration of its consumer properties by making the polyester fabric photochemically active as an example.

Photochemically active materials exposed to sunlight destroy adsorbed organic contaminants, i.e., they are self-cleaning. The simplest method of endowing materials with photochemical properties is coating their surface with a film based onnanosols of crystalline titanium dioxide $\left(\mathrm{TiO}_{2}\right)$ in the form of anatase that is an effective catalyst.

Quite a lot of self-cleaning glasses and construction materials with photocatalytic properties are being produced now. Undoubtedly, there is also a demand for self-cleaning textile fabrics that can be used for decorative and trimming purposes. These properties are especially important for synthetic, and above all polyester, fabrics. Theseare widely used for housing decoration, making curtains and other decorative interior design elements.

Fabrics with such properties havenot been produced yet, although the scientific foundations for their production are being actively studied. For example, the authors of works [11-15] show that it is possible to make fabrics of different chemical compositions highly photochemically active by coating them with $\mathrm{TiO}_{2}$ nanoparticles. However, to achieve the necessary result, almost all researchers, in a similar way as for obtaining self-cleaning glasses and construction materials, deposit a very large amount of $\mathrm{TiO}_{2}$ on a fibrous material. As a result, the modifier is not fixed firmly on the fibres, but is deposited in the inter-fibre space. This worsens the performance characteristics of the fabric. Additionally, the excess $\mathrm{TiO}_{2}$ is washed out, peels off, or wears off as the fabric is used. Some of the researchers [16-18] are trying to solve this problem by applying crosslinking agents. When they are used, the $\mathrm{TiO}_{2}$ adhesion to the fibrous substrate becomes higher but even in this case, $\mathrm{TiO}_{2}$ is deposited on the fabric in excessive quantities. Additionally, crosslinking has a negative effect on the properties of the fabric making it more rigid. The result of such modification is a fabric that has lost its softness and drapability and has become a composite material whose characteristics do not meet the requirements oftraditional fabrics.

In contrast to the above-mentioned studies, in work [19], we suggested coating a polyester fibre material with a very small number of $\mathrm{TiO}_{2}$ nanoparticles. As a result, an ultrathin coating of these particles is formed on the fibre surface. $\mathrm{TiO}_{2}$ adhesion to the fibrous substrate is ensured by preliminary activation of the polyester fibre based on controlled weak hydrolysis of the fibre-forming polymer (polyethylene terephthalate) macromolecules localized on the surface.

The effectiveness of different methods of polyester fibre preliminary activation was analysed by us in works [20-24]. Thesestudies showed that activation increased the content of oxygen-containing groups on the fibre surface and the fibre roughness degree. This led to higher $\mathrm{TiO}_{2}$ adhesion to its surface. This means that it is possible to deposit $\mathrm{TiO}_{2}$ nanoparticles on fibrous materials in quantities sufficient for the formation of a continuous photochemically active coating on every thread, but insufficient for their deposition in the inter-fibre space. We established that modification even with such small $\mathrm{TiO}_{2}$ amount makes a polyester fabric capable of discolouring coloured contaminants on its surface [19], but the modified fabric does not acquire the ability to inhibit the vital activity of microorganisms.

The authors of $[25,26]$ showed that the main mechanism forinhibiting bacteria with $\mathrm{TiO}_{2}$-coated materials wasphotocatalytic. Based on this, we suggested that the absence of biocidal properties in a modified polyester fabric is explained by the fact that when a polyester fabric coated with a small amount of $\mathrm{TiO}_{2}$ is exposedto light, the number of the active radicals generated is insufficient to 
inhibit the activity of bacteria. To increase the photochemical activity of a modified polyester fabric we suggested raising the photochemical activity of the modifier itself- $-\mathrm{TiO}_{2}$. It is known that one of the simple ways of achieving this goal is the doping of the $\mathrm{TiO}_{2}$ crystal lattice with several other elements. Doping of $\mathrm{TiO}_{2}$ with metals significantly increases the redox potential of the formed radicals and increases quantum efficiency by reducing the degree of recombination of electrons and holes. This leads to an increase in the activity of the photocatalyst. For example, high photocatalytic activity has beenregistered in $\mathrm{TiO}_{2}$ doped with iron and silver [27-30]. Works [31,32] confirm that doping with metals increases the capacity of $\mathrm{TiO}_{2}$ nanoparticles to inactivate pathogenic microorganisms.

The aim of the present work was to form ultrathin wear-resistant coatings based on $\mathrm{TiO}_{2}$ of increased photochemical activity on the surface of polyester fabric fibres. The purpose of the coatings is to create a polyester material capable of destroying adsorbed organic contaminants and inhibiting the vital activity of pathogenic bacteria while, at the same time, retaining good consumer characteristics.

\section{Materials and Methods}

\subsection{Materials}

The object of the study in this work was a polyester basket weave fabric with $180 \pm 10 \mathrm{~g} / \mathrm{m}^{2}$ area density, $216 \pm 4$ ends per $10 \mathrm{~cm}$ and $203 \pm 4$ picks per $10 \mathrm{~cm}$ (produced by "Y.R.C. Textile Co., Ltd", Bangkok, Thailand), bought at a store.

The polyester fabric was modified with undoped $\mathrm{TiO}_{2}$ nanoparticles and iron- and silver-doped $\mathrm{TiO}_{2}$ nanoparticles obtained via sol-gel synthesis. In the synthesis procedure we used $\mathrm{Ti}_{3}\left(\mathrm{C}_{3} \mathrm{H}_{7} \mathrm{O}\right)_{4}$ (97\%, purchased from the Sigma-Aldrich company, Saint Louis, MO, United States), $\mathrm{C}_{3} \mathrm{H}_{7} \mathrm{OH}$ (c.p., purchased from the CHIMMED company, Moscow, Russia), concentrated $\mathrm{HNO}_{3}$ (c.p., purchased from the CHIMMED company), $\mathrm{Fe}_{3} \mathrm{O}_{4}$ (97\%, purchased from the Sigma-Aldrich company), $\mathrm{AgNO}_{3}$ ( $\geq 99 \%$, purchased from the Sigma-Aldrich company). For polyester fabric activation we used $\mathrm{NaOH}$ (c.p., purchased from the CHIMMED company). To evaluate the physical activity, we employed the eosin dye (tetrabromofluorescein) (analysis-acs, purchased from the Kemikon company, Wcega Tower, singapore) as an indicator.

\subsection{Methods}

\subsubsection{Synthesis of Nanoparticles}

The basis of the synthesis procedure of $\mathrm{TiO}_{2}$ nanoparticles was the sol-gel method of obtaining monodisperse titanium dioxide powders through hydrolysis of a corresponding alkoxide with the general formula $\mathrm{Ti}(\mathrm{OR})_{\mathrm{n}}$ [33], where $\mathrm{R}$ is the alkoxide radical, from an alcoholic solution. $\mathrm{TiO}_{2}$ was obtained in the sol form by $\mathrm{Ti}\left(\mathrm{C}_{3} \mathrm{H}_{7} \mathrm{O}\right)_{4}$ hydrolysis in an aqueous medium with $0.1 \mathrm{M} \mathrm{HNO}_{3}$ The amount of $0.0405 \mathrm{M} \mathrm{Ti}\left(\mathrm{C}_{3} \mathrm{H}_{7} \mathrm{O}\right)_{4}$ was mixed with $0.21 \mathrm{M} \mathrm{C}_{3} \mathrm{H}_{7} \mathrm{OH}$. The obtained solution was added to an excess of $0.1 \mathrm{M} \mathrm{HNO}_{3}$ at $70{ }^{\circ} \mathrm{C}$. The immediate result was a loose sediment of hydrolysis products that was then mixed at $80^{\circ} \mathrm{C}$ for $5 \mathrm{~h}$ till a transparent $\mathrm{TiO}_{2}$ sol was formed.

$\mathrm{TiO}_{2}$ doped with $\mathrm{Fe}_{3} \mathrm{O}_{4}$ nanoparticles was obtained in a one-stage process by mixing two solutions under ultrasound treatment [34]. The first solution was obtained by peptizing $4.3 \times 10^{-5}$ moles $\mathrm{Fe}_{3} \mathrm{O}_{4}$ in a $0.1 \mathrm{M}$ solution of concentrated $\mathrm{HNO}_{3}$ under mixing and heating to $70^{\circ} \mathrm{C}$, and the second solution was prepared by mixing $0.0405 \mathrm{M} \mathrm{Ti}\left(\mathrm{C}_{3} \mathrm{H}_{7} \mathrm{O}\right)_{4}$ with $0.21 \mathrm{M} \mathrm{C}_{3} \mathrm{H}_{7} \mathrm{OH}$. The immediate result was loose sediment of hydrolysis products that was then mixed at $80{ }^{\circ} \mathrm{C}$ for $5 \mathrm{~h}$ until a transparent $\mathrm{TiO}_{2}$ sol was formed. The result of the synthesis was a $\mathrm{TiO}_{2} / \mathrm{Fe}_{3} \mathrm{O}_{4}$ nanocomposite whose structure and main properties were described in detail in work [34].

The synthesis of $\mathrm{TiO}_{2}$ doped with silver nanoparticles was carried out in one step by mixing two solutions under ultrasound treatment. The first one was obtained through peptization of $1.7 \times 10^{-5}$ mole $\mathrm{AgNO}_{3}$ in a $0.1 \mathrm{M}$ solution of concentrated $\mathrm{HNO}_{3}$ under mixing and heating to $70{ }^{\circ} \mathrm{C}$, while the second solution was prepared by mixing $0.0405 \mathrm{M} \mathrm{Ti}\left(\mathrm{C}_{3} \mathrm{H}_{7} \mathrm{O}\right)_{4}$ with $0.21 \mathrm{M} \mathrm{C}_{3} \mathrm{H}_{7} \mathrm{OH}$. The immediate result 
was loose sediment of hydrolysis products which was then mixed at $80{ }^{\circ} \mathrm{C}$ for $5 \mathrm{~h}$ until a transparent $\mathrm{TiO}_{2}$ sol was formed [35].

\subsubsection{Polyester Fabric Preparation and Modification}

We deposited nanosols containing different $\mathrm{TiO}_{2}$ modifications on the polyester fabric by dipping and then drying it at $40{ }^{\circ} \mathrm{C}$. We regulated the $\mathrm{TiO}_{2}$ nanosol concentration so that the fabric surface contained $8 \mathrm{~g} / \mathrm{m}^{2} \mathrm{TiO}_{2}$.

$\mathrm{TiO}_{2}$ nanosol was deposited on the polyester fabric that had been activated in advance. Based on the preliminary studies, we chose two methods for polyester fabric activation before $\mathrm{TiO}_{2}$ modification: sodium hydroxide solution treatment (chemical activation) [21] and dielectric barrier discharge surface treatment (plasma activation) [24]. For chemical activation of the polyester fabric, we treated it with a sodium hydroxide solution with a concentration of $3.75 \mathrm{~g} / \mathrm{L}$ at $100{ }^{\circ} \mathrm{C}$ for $20 \mathrm{~min}$. The surface barrier-discharge plasma activation was performed on an original apparatus (whose design is described in work [24]) for $5 \mathrm{~s}$. at the output voltage of $3.5 \mathrm{kV}$ and frequency of $22 \mathrm{kHz}$.

\subsubsection{Testing of Modified Polyester Fabric}

The photochemical activity of the modified fabric was determined by the degree of discolouration of a drop of the eosin dye solution (tetrabromofluorescein) exposed to UV radiation for 5-250 min. Among the dyes traditionally used for studying the photochemical activity of catalysts, we chose eosin because it allows the minimization ofthe experimental error, as it is poorly adsorbed by $\mathrm{TiO}_{2}$ [36]. In addition, eosin has an acidic nature and, consequently, is not adsorbed by the polyester fabric. The UV-radiation source was a 6W UV light bulb (produced by "VilberLourmat") with the radiation maximum at $365 \mathrm{~nm}$. We chose a source with such spectral characteristics because there is an absorption maximum at 300-400 $\mathrm{nm}$ on the $\mathrm{TiO}_{2}$ nanoparticle spectrum.

The effectiveness of the modified fabric photocatalytic activity was determined by the calorimetric method-by the colour intensity of an indicator drop placed on the fabric surface. The colour intensity was measured after the sample was exposed to different doses of UV-radiation. The colour intensity of the drop placed on the sample surface was quantitatively estimated by the colour differences that were measured by a colour measurement complex equipped with the program "Kolorist" (version 4.2.1994, 2000, the authors are V.S. Pobedinsky, F.Yu. Telegin, I.A. Danilin).

The stability of the polyester fabric self-cleaning ability and resistance to washing and abrasion were determined by changes in its photochemical activity after the fabric was washed three times in an automatic washing machine in the standard regime for blended and synthetic fabrics (with a detergent at a temperature of $40{ }^{\circ} \mathrm{C}$ within $60 \mathrm{~min}$ with subsequent drying in the air) or subjected to abrasion 10 times. The abrasive effect consisted of the simultaneous action of normal applied load and shear load produced by the application of a horizontal force. Such effect was realized by using a special apparatus PT-4 for evaluating the colour resistance to abrasion. A fabric sample was pulled onto the apparatus stage and abraded with a calico piece fixed onto a protruding rubber stopper. The abrasion was produced by pulling the handle to move the stage by $10 \mathrm{~cm} 10$ times in the forward and 10 times in the reverse direction. The total force applied by the stopper to the stage was $9.8 \mathrm{~N}$. Ten parallel measurements were made.

We evaluated the softness and drapability of the fabric in index of stiffness (inflexibility). We determined the stiffness in accordance with GOST 10550-75 by the simplified console method. A $4 \mathrm{~cm} \times 6 \mathrm{~cm}$ fabric sample was fixed in a special clip in the form of a console by one narrow end. After $20 \mathrm{~s}$, the deflection angle of the sample under its own weight was measured. The stiffness calculation was carried out according to the results of 5 parallel measurements according to the formula:

$$
G=\left(\varphi_{\text {fin }}-90\right):\left(\varphi_{\text {or }}-90\right)
$$


where $G$ is the fabric stiffness; $\varphi_{\text {fin }}$ is the deflection angle of the coated sample, degrees; $\varphi_{\text {or }}$ is the deviation angle of the original sample, degrees.

The higher the stiffness of the sample - the more the stiffness indicator differs from 1.

The surface morphology was studied by an atomic-force scanning probe microscope Solver-47Pro ("NT MTD", Zelenograd, Russia), a scanning electron microscope NVision 40 ("Carl Zeiss", Jena, Germany), and an optical microscope ("Biomed", Moscow, Russia) equipped with a webcamera (1.3 MP).

The adhesion properties of the coatings and their stiffness were obtained based on the earlier studies conducted by the force spectroscopy method on an atomic-force scanning probe microscope Solver-47Pro ("NT MTD", Zelenograd, Russia). The method is based on measuring the cantilever displacement (deflection degree) at different distances between the probe and the sample. Work [37] contains a detailed description of the method. The adhesion was determined by Hooke's law based on the known stiffness coefficient of the probe used $(3.5 \mathrm{~N} / \mathrm{m})$ when the probe moved away from the surface. The relative stiffness was characterized by the relative cantilever deflection when the probe approached the surface. The error of these measurements was $\sim 5 \%$.

We evaluated the effect of the modified fibrous material on the vital activity of pathogenic microorganisms using typical test cultures: Staphylococcus aureus 6538-P ATCC=209-P FDA (hereafter S. aureus) and Escherichia coli strain M-17 (hereafter E. coli)—gram-negative and gram-positive bacterial cultures, respectively-Candida albicansCCM 8261 (ATCC 90028) (hereafter C. albicans)—yeast-like microscopic fungi. Thiswas done by conducting a "counting" test used for estimating the effectiveness of antimicrobial treatment of textile materials with non-migrating compounds chemically bound with the fibre [38]. It is based on counting the number of microbial colonies formed as a result of a 24-h contact of a standard sample of a modified fibrous material with a physiological solution containing a certain number of microbial colonies introduced to it in the form of a suspension [38]. To avoid errors in counting the microorganism colonies and reduce the duration of the counting procedure, we evaluated the effect by determining the microbial culture growth by the nephelometric method (based on the solution turbidity changes).

The tensile strength and breaking elongation of the polyester fabric were determined in accordance with GOST 102132-73 on a modernized tensile testing machine 2099 P-5.

\section{Results and Discussion}

As work [19] showed, depositing a small amount of $\mathrm{TiO}_{2}$ nanoparticles onto a pre-activated polyester fabric leads to the formation of an ultrathin continuous coating on thesurface of every thread of the fabric. The best qualitative characteristics and high adhesion are achieved at the $\mathrm{TiO}_{2}$ content of $8 \mathrm{~g} / \mathrm{m}^{2}$ on the surface. As the comparison of micrographs 1a and 2a (Figure 1) shows, the formation of such coatings is not accompanied by $\mathrm{TiO}_{2}$ sedimentation in the inter-fibre space. Table 1 shows the stiffness (inflexibility) of fabrics with different $\mathrm{TiO}_{2}$ surface content. It follows from Table 1 that the stiffness of the PEF fabric after application of $\mathrm{TiO}_{2}$ increases very little. This proves that the fabric retains high performance characteristics - softness and good drapability.

Table 1. The stiffness of $\mathrm{TiO}_{2}$-coated PEF fabrics.

\begin{tabular}{cc}
\hline Composition of the Modified Polyester Fabric Coating & Stiffness of PEF Fabric \\
\hline Uncoated Fabric & 1 \\
$\mathrm{TiO}_{2}$ nanoparticles, $4 \mathrm{~g} / \mathrm{m}^{2}$ & 1.27 \\
$\mathrm{TiO}_{2}$ nanoparticles, $8 \mathrm{~g} / \mathrm{m}^{2}$ & 1.53 \\
$\mathrm{TiO}_{2}$ nanoparticles, $16 \mathrm{~g} / \mathrm{m}^{2}$ & 2.00 \\
\hline
\end{tabular}

The images of the morphology of the coating obtained by the scanning electron (Figure $1 \mathrm{~b}, \mathrm{e}$ ) and atomic-force microscopy (Figure 1c,f)show that the coating has a nanostructure and are ordered. 


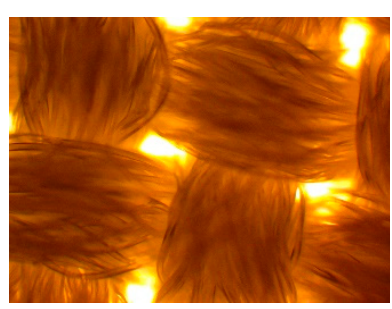

(a)

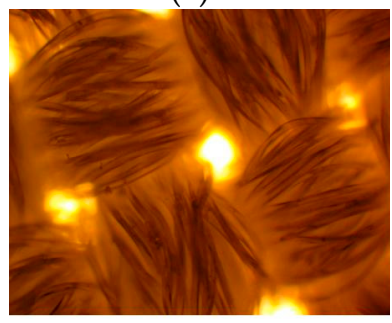

(d)

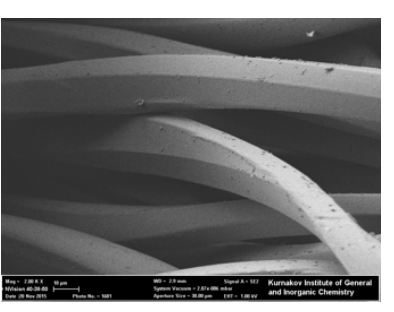

(b)

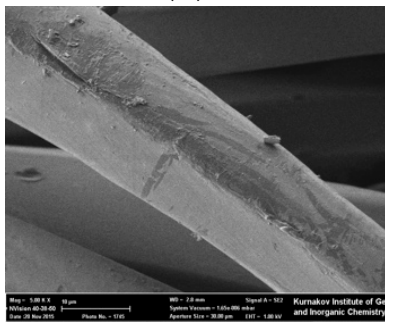

(e)

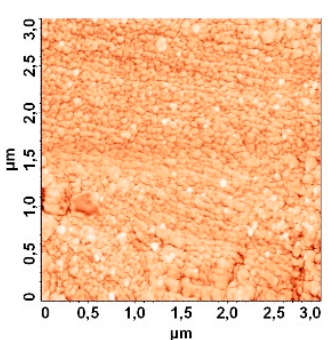

(c)

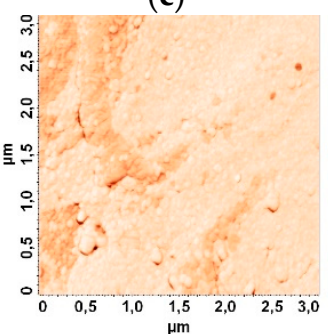

(f)

Figure 1. Surface morphology of the polyester fabric activated with a $\mathrm{NaOH}$ solution: (a-c) without a coating; (d-f) with a $\mathrm{TiO}_{2}$-based coating. Visualization by the methods of: (a) Optical microscopy; (b) Scanning electron microscopy; (c) Atomic-force microscopy.

The coating formed is photochemically active, which is confirmed by discolouration of a dye drop on its surface when the coating is exposed to UVradiation (Figure 2).

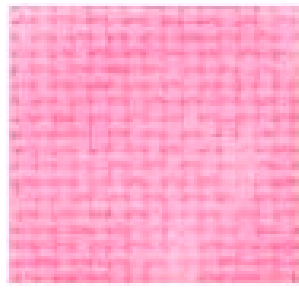

(a)

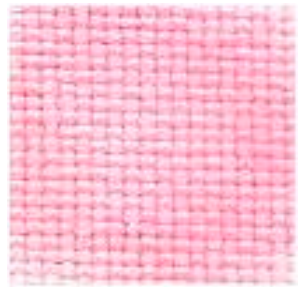

(b)

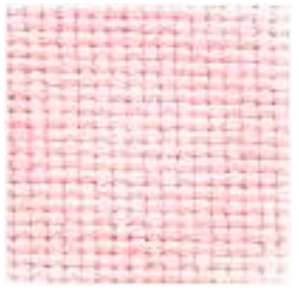

(c)

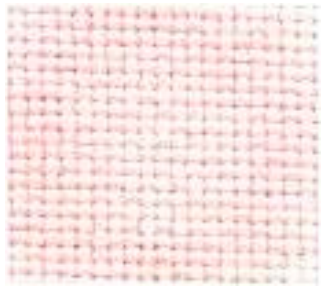

(d)

Figure 2. $\mathrm{TiO}_{2}$-modified polyester fabric with an eosin drop: (a) without UV-radiation; (b) after 20-min exposure to UV-radiation; (c) after 40-min exposure to UV-radiation; (d) after 60-min exposure to UV-radiation.

The uniformity of distribution of the photoactive centres on the polyester fibre surface was achieved by using a highly dilute solution of $\mathrm{TiO}_{2}$ hydrosol with small-sized particles and high sedimentation stability. The most effective methods of polyester fabric preactivation, facilitating the formation of the maximum number of active oxygen-containing groups on the polyester fibres and increasing the roughness of their surface were found to be fabric treatment with a $\mathrm{NaOH}$ solution with a concentration of $3.75 \mathrm{~g} / \mathrm{L}$ at $100{ }^{\circ} \mathrm{C}$ for $20 \mathrm{~min}$ and surface-barrier discharge plasma treatment for $5 \mathrm{~s}$. at the output voltage of $3.5 \mathrm{kV}$ and frequency of $22 \mathrm{kHz}$. The drawback of polyester fabric modification with $\mathrm{TiO}_{2}$ nanoparticles is, as was mentioned above, the inability of the modifiedpolyester fabric to inactivate pathogenic bacteria, which, in our opinion, is a result of the fact that its photochemical activity is insufficient for this purpose.

In the present work, we used $\mathrm{TiO}_{2}$ nanoparticles doped with iron and silver to modify a polyester fabric in order to achieve a further increase in its photochemical activity. The modification was carried out at the parameters that had been determined earlier and create the conditions favourable for coating formation. Figure 3 shows dependences allowing a comparison of the discolouration effectiveness of the eosin dye exposed to UV-radiation when it is deposited on a polyester fabric modified with undoped 
and doped $\mathrm{TiO}_{2}$ and preactivated by different methods The rate of photochemical decomposition of the eosin dye was determined by the slope of the dependences of the sample colour changes on the UV-exposure duration. The figure shows that $\mathrm{TiO}_{2}$ doping leads to a significant increase in the rate of the eosin photochemical decomposition, which is especially fast in the first 60 min of UV-exposure. The largest increase in the polyester fabric photochemical activity after the fabric modification with $\mathrm{TiO}_{2}$ nanoparticles doped with metals is observed when silver is used as the doping element. It must be said that this also results in considerable growth in the dye decomposition degree.

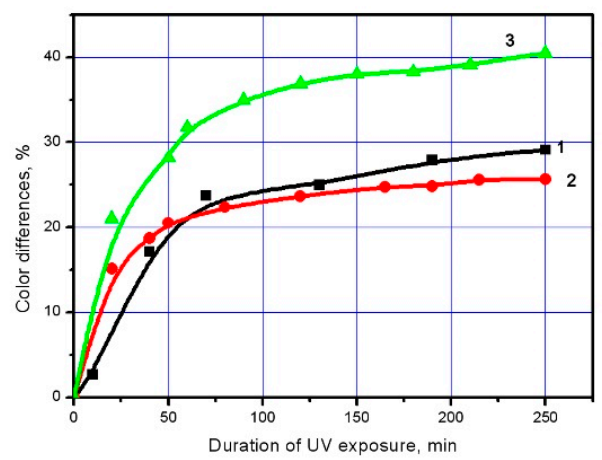

(a)

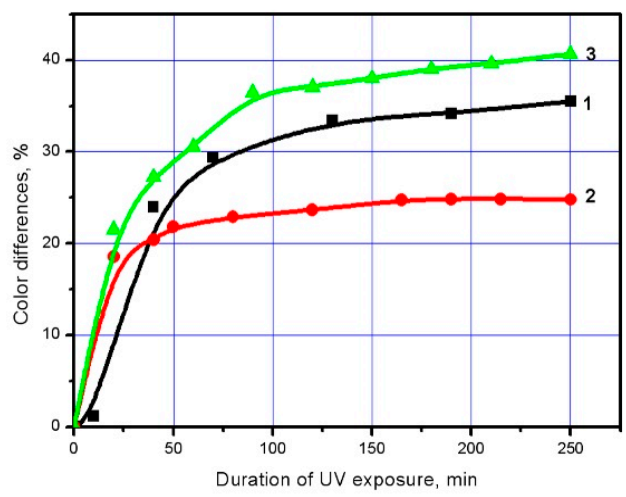

(b)

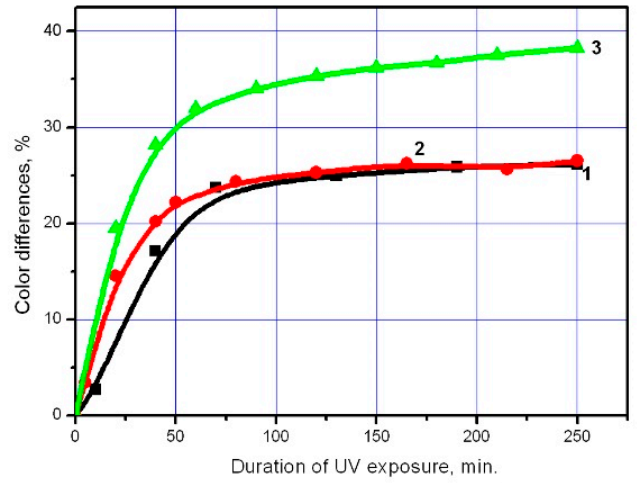

(c)

Figure 3. Colour differences in the eosin drop placedon a polyester fabric: 1 - Coated with $\mathrm{TiO}_{2}$ nanoparticles; 2-Coated with $\mathrm{TiO}_{2}$ nanoparticles doped with iron; 3-Coated with $\mathrm{TiO}_{2}$ nanoparticles doped with silver; (a) Nonactivatedpolyester fabric; (b) Polyester fabric pre-activated with a $\mathrm{NaOH}$ solution with a concentration of $3.75 \mathrm{~g} / \mathrm{L}$; (c) Polyester fabric pre-activated with surface-barrier discharge plasma for $5 \mathrm{~s}$.

Figure 3 also allows evaluating the preactivation effect on the photochemical properties of a polyester fabric modified with $\mathrm{TiO}_{2}$ nanoparticles doped with metals and undoped ones. The Figure shows that, in comparison with undoped $\mathrm{TiO}_{2}$, activation has the least effect on the rate of the dyephotochemical decomposition by a polyester fabric coated with $\mathrm{TiO}_{2}$ nanoparticles doped with metals. This is probably due to a change in the adhesive properties of $\mathrm{TiO}_{2}$ as a result of doping with metals.

One of the important characteristics determining the possibility of practical application of a modified polyester fabric is the resistance of the achieved properties to dry friction and washing. Figure 4 presents data allowing us to compare changes caused by abrasion in the photochemical activity of a polyester fabric modified with undoped $\mathrm{TiO}_{2}$ nanoparticles and $\mathrm{TiO}_{2}$ nanoparticles doped with iron and silver. The figure shows that dry friction leads to decrease in the rate and intensity of the dye photochemical decomposition by the polyester fabric coated with $\mathrm{TiO}_{2}$ nanoparticles doped with iron, which is, presumably, the result of partial removal of the loosely adhering $\mathrm{TiO}_{2}$ caused by 
intensive abrasion. However, if the modifier is undoped $\mathrm{TiO}_{2}$ nanoparticles and those doped with silver, the polyester fabric photochemical activity decreases slightly or practically unchanged.

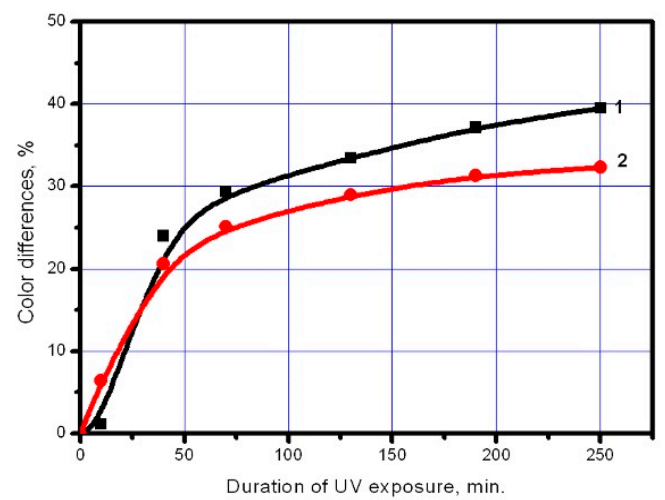

(a)

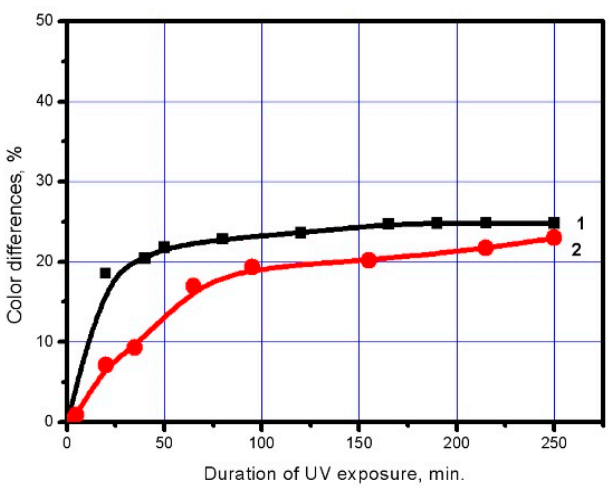

(b)

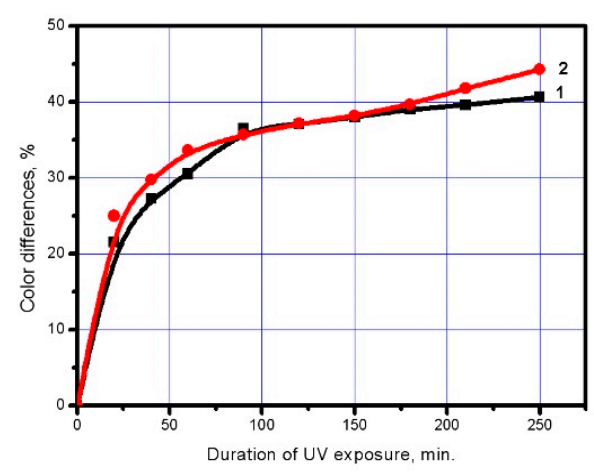

(c)

Figure 4. Colour differences in eosin for $\mathrm{NaOH}$-activated $(3.75 \mathrm{~g} / \mathrm{L})$ polyester fabric before it is subjected to abrasion (1) and after it (2). Fabric with a $\mathrm{TiO}_{2}$ coating $\left(8 \mathrm{~g} / \mathrm{cm}^{2}\right)$ consisting of: (a) Undopednanoparticles; (b) Nanoparticles doped with iron; (c) Nanoparticles doped with silver.

To find out the reasons for such result, we analysed the morphology of the coating before and after it were subjected to abrasion by the atomic-force microscopy method. The study results are given in Figure 5 and Table 2.

Table 2. Adhesion properties and stiffness of coatings formed on a polyester fabric.

\begin{tabular}{cccc}
\hline \multirow{2}{*}{$\begin{array}{c}\text { Composition of the Modified } \\
\text { Polyester Fabric Coating }\end{array}$} & \multicolumn{2}{c}{ Probe Adhesion to the Coating, $\mathbf{n N}$} & \multicolumn{2}{c}{ Relative Stiffness, nA/nm } \\
\cline { 2 - 4 } & Initial Sample & $\begin{array}{c}\text { Sample Subjected } \\
\text { to Abrasion }\end{array}$ & $\begin{array}{c}\text { Initial Sample } \\
\text { Sample Subjected } \\
\text { to Abrasion }\end{array}$ \\
\hline $\mathrm{TiO}_{2}$ undoped nanoparticles & 11.6 & 7.7 & 0.052 \\
$\mathrm{TiO}_{2}$ nanoparticles doped with iron & 16.8 & 21.0 & 0.058 \\
$\mathrm{TiO}_{2}$ nanoparticles doped with silver & 19.8 & 15.2 & 0.053 \\
\hline
\end{tabular}

The figure shows that the coating based on $\mathrm{TiO}_{2}$ undoped nanoparticles and $\mathrm{TiO}_{2}$ doped with silver becomes denser when subjected to abrasion. The ordering and higher density of the coating structure, evidently, has a positive effect on the photochemical activity. The observed regularity is confirmed by the data in Table 2. 


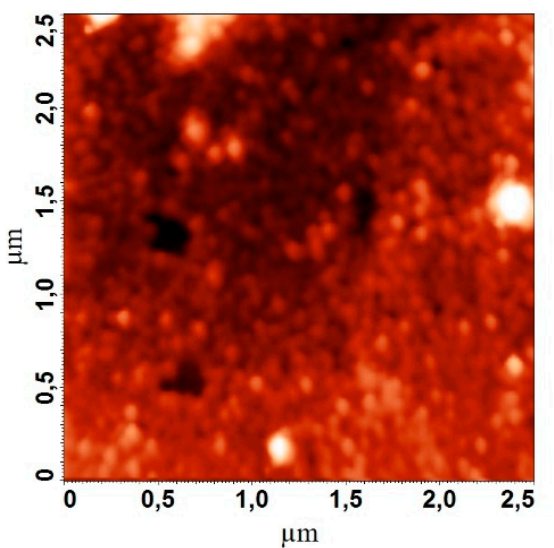

(a)

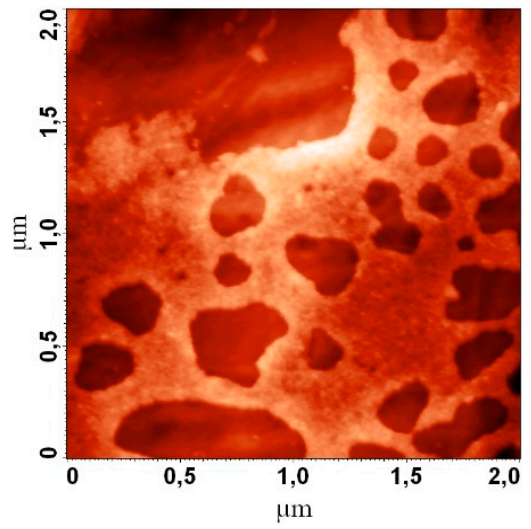

(c)

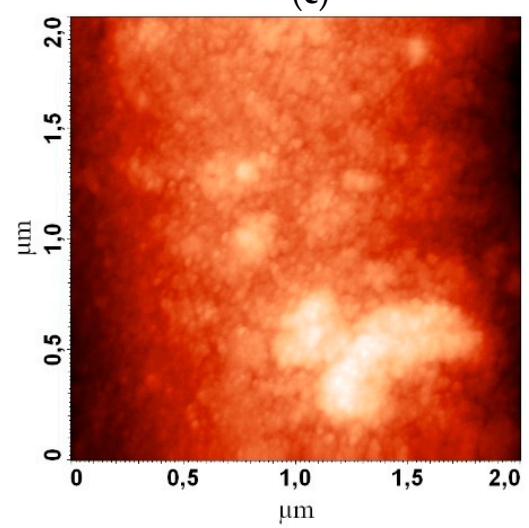

(e)
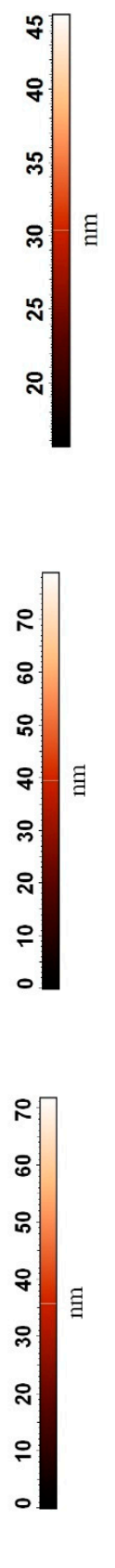

Figure 5. Effect of abrasion on the polyester fibre surface morphology in a fabric modified with $\mathrm{TiO}_{2}$ nanoparticles doped with iron and silver: (a) Coating of undoped $\mathrm{TiO}_{2} ;(\mathbf{b})$ coating of undoped $\mathrm{TiO}_{2}$ after abrasion; (c) coating of $\mathrm{TiO}_{2}$ doped with iron; (d) coating of $\mathrm{TiO}_{2}$ doped with iron after abrasion; (e) coating of $\mathrm{TiO}_{2}$ doped with silver; (f) coating of $\mathrm{TiO}_{2}$ doped with silver after abrasion. AFM method.

The scanning area is $2 \mu \mathrm{m} \times 2 \mu \mathrm{m}$.

As the table shows, the probe adhesion to the coating based on $\mathrm{TiO}_{2}$ undoped nanoparticles and $\mathrm{TiO}_{2}$ nanoparticles doped with iron increases under abrasion. It means that the coating becomes looser. The probe adhesion to the coating based on $\mathrm{TiO}_{2}$ nanoparticles doped with silver, in contrast, becomes weaker. This indicates that the coating becomes denser. Similar conclusions can be also made after analysing the relative stiffness of the coatings. It is determined by the relative value of the cantilever deflection as the probe approaches the surface. A stiffer surface needs a smaller displacement for 
obtaining the required change in the recorded signal that is proportional to the cantilever deflection. The table shows that the coating based on $\mathrm{TiO}_{2}$ nanoparticles doped with iron is less stiff.

Figure 6 presents dependences reflecting the stability of the photochemical activity of a polyester fabric modified by undoped $\mathrm{TiO}_{2}$ nanoparticles and those doped with metals when the fabric is washed.

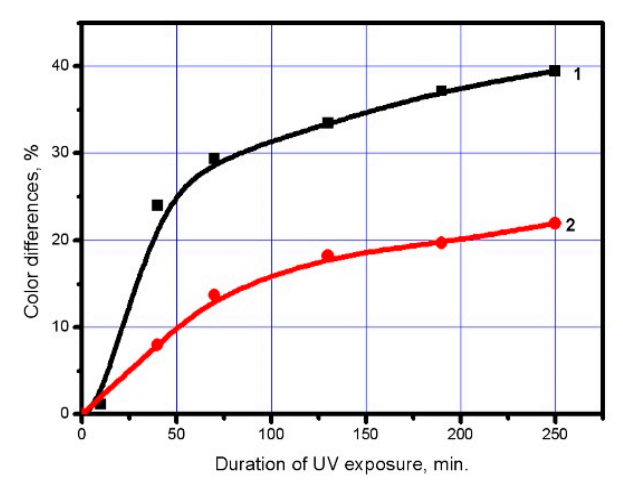

(a)

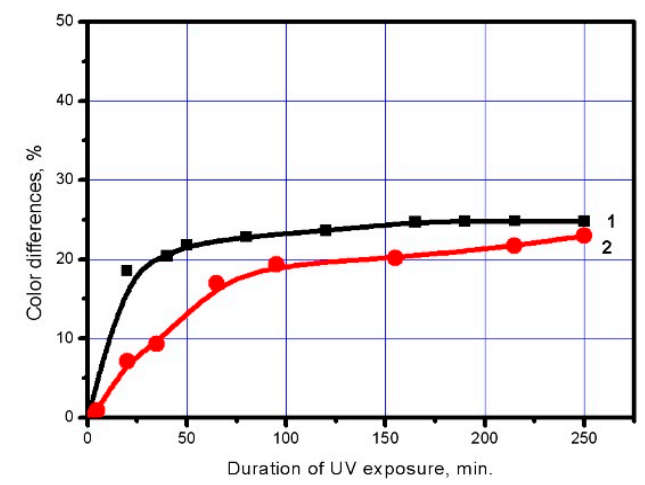

(b)

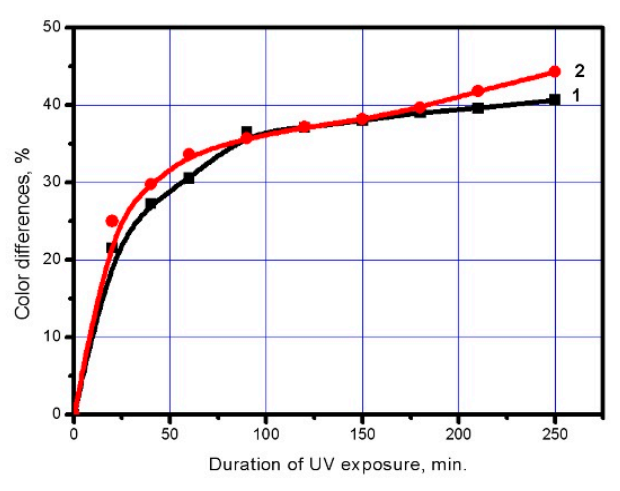

(c)

Figure 6. Differences in eosin colour before washing (1) and after washing (2) in the polyester fabric activated with $\mathrm{NaOH}(3.75 \mathrm{~g} / \mathrm{L})$. Fabric with a coating based on $\left(8 \mathrm{~g} / \mathrm{cm}^{2}\right)$ : (a) Undoped $\mathrm{TiO}_{2}$ nanoparticles; (b) $\mathrm{TiO}_{2}$ nanoparticles doped with iron; (c) $\mathrm{TiO}_{2}$ nanoparticles doped with silver.

As the figure shows, washing leads to an insignificant reduction in the photochemical activity of the polyester fabric modified with all $\mathrm{TiO}_{2}$ types. This is, evidently, the result of partial removal of the loosely adhering $\mathrm{TiO}_{2}$ from the polyester fabric fibre surface. This hypothesis is confirmed by Figure 7 that shows scanning electron microscopy images of the fabric surface coated with $\mathrm{TiO}_{2}$ before and after the washing.

The fabric with the highest photochemical activity after the washing is the one modified with $\mathrm{TiO}_{2}$ nanoparticles doped with silver. In combination with the above-mentioned data on the extremely high resistance of this coating to dry friction, these results indicate that the coating-based of $\mathrm{TiO}_{2}$ nanoparticles doped with silver has a dense ordered structure and high adhesion to the fibrous substrate.

It is known that for the photocatalytical inactivation of pathogenic bacteria, the bacterial cells must be sorbedby a coating based on $\mathrm{TiO}_{2}$ nanoparticles $[39,40]$. Therefore, to evaluate the ability of a modified polyester fabric to inhibit the activity of pathogenic organisms, we used a "counting" test in which the fabric got in contact with suspensions of test organisms, allowing the coating to sorb the latter. The obtained data are given in Table 3. 


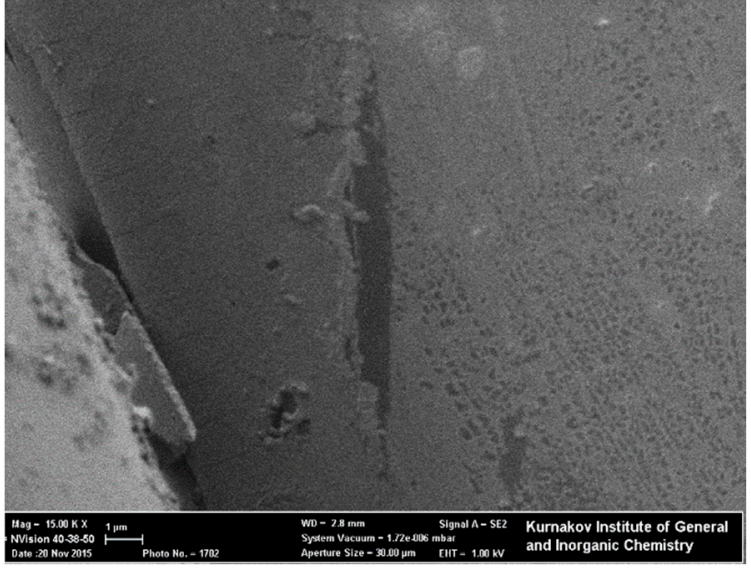

(a)

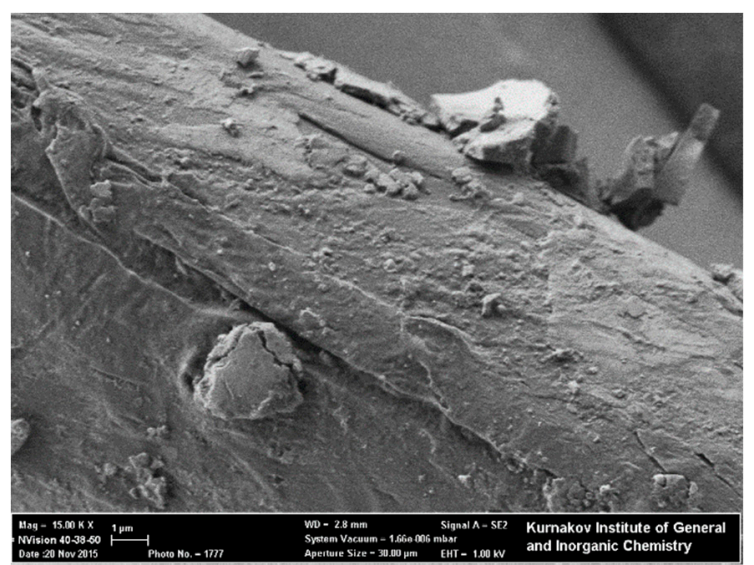

(b)

Figure 7. Polyester fabric fibres coated with $\mathrm{TiO}_{2}$ nanoparticles $\left(8 \mathrm{~g} / \mathrm{cm}^{2}\right)$ before the washing (a); and after the washing (b). Scanning electron microscopy method.

Table 3. Ability of a $\mathrm{TiO}_{2}$-coatedpolyester fabric to inhibit the vital activity of pathogenic bacteria.

\begin{tabular}{cccc}
\hline Composition of the Modified Polyester & \multicolumn{3}{c}{ Growth $(+)$ or Inhibition (-) of Pathogenic Cultures, $\%$} \\
\cline { 2 - 4 } Fabric Coating & E. coli & S. aureus & C. albicans \\
\hline $\mathrm{TiO}_{2}$ nanoparticles & +31 & +63 & +83 \\
$\mathrm{TiO}_{2}$ nanoparticles doped with iron & -27 & +53 & +61 \\
$\mathrm{TiO}_{2}$ nanoparticles doped with silver & -50 & +35 & +8 \\
\hline
\end{tabular}

It follows, from Table 3, that the polyester fabric coated with $\mathrm{TiO}_{2}$ does not inactivate the gram-positive bacteria $S$. aureus and opportunistic fungi of the genus Candida. However, when the polyester fabric is modified with $\mathrm{TiO}_{2}$ nanoparticles doped with iron and silver, it becomes capable of inactivating the gram-negative bacteria E. coli. These bacteria are more sensitive to the pathophysiological effect of active radicals generated by UV radiation than the gram-positive ones. Such sensitivity is determined, first of all, by the specific structure of their cell walls. As Table 3 shows, $\mathrm{TiO}_{2}$ nanoparticles doped with silver have much higher biocidal activity against $E$. coli, which agrees with the conclusions made in works [41,42]. A coating of $\mathrm{TiO}_{2}$ nanoparticles doped with silver contains a small number of silver nanoparticles retaining their own biological activity. However, this is not the reason for the coating biocidal action. In work [43], we showed that the vital activity of the gram-negative bacteria $E$. coli is inhibited by the active radicals generated by $\mathrm{TiO}_{2}$ nanoparticles doped with silver.

A fabric coated with $\mathrm{TiO}_{2}$ has a self-cleaning ability when exposed to UV-radiation, which is known to cause degradation of many polymers. It can be expected that long-time exposure of afibrous material can lead to the loss of its strength. Some researchers believe that depositing a photoactive coating on a fibre can protect it from photodegradation [44]. Others, on the contrary, suppose that such coating can facilitate fibre degradation [45]. We have also evaluated the effect of $\mathrm{TiO}_{2}$-based coatings formed on a polyester fabric on its physical and mechanical properties. The obtained data are shown in Table 4.

The table shows that exposure to UV radiation of both the untreated polyester fabric and the one modified with $\mathrm{TiO}_{2}$ nanoparticles for 250 min does not reduce its tensile strength and breaking elongation. 
Table 4. The main physico-mechanical characteristics of a polyester fabric with $\mathrm{TiO}_{2}$ nanoparticle coatings.

\begin{tabular}{ccc}
\hline Type of Polyester Fabric & Specific Tensile Strength, MPa & Relative Breaking Elongation, \% \\
\hline Untreated & $1410 \pm 46$ & $26.7 \pm 4.0$ \\
Activated with 0.375 mol/L NaOH & $1318 \pm 45$ & $25.6 \pm 1.2$ \\
Untreated, after 250 min UV-exposure & $1381 \pm 67$ & $27.0 \pm 1.6$ \\
With a $\mathrm{TiO}_{2}$-based coating after NaOH activation & $1507 \pm 64$ & $23.8 \pm 1.2$ \\
With a $\mathrm{TiO}_{2}$-based coating after NaOH activation and 250 min UV-exposure & $1460 \pm 57$ & $23.8 \pm 1.6$ \\
\hline
\end{tabular}

\section{Conclusions}

To increase the photoactive coating adhesion to a polyester fabric, we carried out its activation at the preliminary stage in order to form active oxygen-containing groups on the polyester fibres and increase the fibre surface roughness. Then, we treated the polyester fabric with a dilute $\mathrm{TiO}_{2}$ nanosol with high sedimentation stability. As a result, an ultrathin ordered coating was formed on the surface of each of the polyester fabric fibres. The coating formation was not accompanied by the $\mathrm{TiO}_{2}$ deposition in the inter-fibre space, which allowed the fabric to retain its softness and good drapability. To improve the photochemical activity of the modified polyester fabric we used $\mathrm{TiO}_{2}$ nanoparticles doped with metals. The use of $\mathrm{TiO}_{2}$ nanoparticles doped with silver as the modifier allowed us to achieve a considerable increase in the photodegradation of the dye adsorbed by the fabric. Since the structure of the coating based on $\mathrm{TiO}_{2}$ nanoparticles doped with silver was dense and ordered, the coating had good wash-resistance and excellent abrasion-resistance. This indicates the durability of coatings based on $\mathrm{TiO}_{2}$ nanoparticles doped with silver and their high consumer characteristics. The use of the above-mentioned nanoparticles also allowed us to make the polyester fabric capable of inhibiting the vital activity of gram-negative bacteria when the fabric is exposed to light Exposure to UV radiation of the fabric modified with $\mathrm{TiO}_{2}$ did not reduce the tensile strength or the breaking elongation of the polyester fabric. Polyester fabrics coated with $\mathrm{TiO}_{2}$ nanoparticle doped with silver can be used in housing decoration, production of curtains and bedding, etc.

Author Contributions: Conceptualization, methodology, writing-original draft preparation, writing-review and editing, N.P.; data curation, investigation, visualization, T.K.; software, investigation, visualization, I.K. All authors have read and agreed to the published version of the manuscript.

Funding: This work was financially supported by the Russian Foundation for Basic Research (RFBR) and the Government of Ivanovo region (project No. 15-48-03064).

Acknowledgments: The authors would like to express their gratitude to A.V. Agafonov and T.V. Gerasimova (G.A. Krestov Institute of Solution Chemistry of the Russian Academy of Sciences) for their help in synthesizing nanosized titanium dioxide, O.Yu. Kuznetsov (Ivanovo State Medical Academy) for his help in the microbiological studies, V.K. Ivanov (Kurnakov Institute of General and Inorganic Chemistry of the Russian Academy of Sciences) for his aid in the scanning electron microscopic studies. The work was done on the equipment of the Center for Collective Use of Scientific Equipment "The Upper Volga Region Center of Physico-Chemical Research" and the Center for Collective Use of Ivanovo State University of Chemistry and Technology.

Conflicts of Interest: The authors declare no conflict of interest.

\section{References}

1. Mahltig, B.; Textor, T. Nanosols and Textiles; World Scientific Publishing Co. Pte. Ltd.: Singapore, 2008 ; p. 224.

2. Gashti, M.P.; Pakdel, E.; Alimohammadi, F. Nanotechnology-based coating techniques for smart textiles. In Active Coatings for Smart Textiles; Woodhead Publishing: Cambridge, UK, 2016; pp. 243-268.

3. Nurhan, O.C.; Buket, A. Sol-Gel Applications in Textile Finishing Processes. In Recent Applications in Sol-Gel Synthesis; INTECH: London, UK, 2017; pp. 253-281.

4. Ismail, W.N.W. Sol-gel technology for innovative fabric finishing-A review. J. Sol-Gel Sci. Technol. 2016, 78, 698-707. [CrossRef]

5. Rivero, P.J.; Urrutia, A.; Goicoechea, J.; Arregui, F.J. Nanomaterials for Functional Textiles and Fibers. Nanoscale Res. Lett. 2015, 10, 501-523. [CrossRef] [PubMed]

6. Galrajani, M.L.; Gupta, D. Emerging techniques for functional finishing of textiles. IJFTR 2011, 36, $388-397$. 
7. Schmidt, H. Considerations about the sol-gel process: From the classical sol-gel route to advanced chemical nanotechnologies. J. Sol-Gel Sci. Technol. 2006, 40, 115-130. [CrossRef]

8. Hench, L.L.; West, J.K. The Sol-Gel Process. Chem. Rev. 1990, 90, 33-72. [CrossRef]

9. Brinker, C.J.; Scherer, G. Sol-Gel Science: The Physics and Chemistry of Sol-Gel Processing; Academic Press: Boston, MA, USA, 1990; p. 908.

10. Li, S.; Huang, J.; Chen, Z.; Chena, G.; Lai, Y. A review on special wettability textiles: Theoretical models, fabrication technologies and multifunctional applications. J. Mater. Chem. A 2017, 5, 31-55. [CrossRef]

11. Chen, C.C.; Wang, C.C. Crosslinking of cotton cellulose with succinic acid in the presence of titanium dioxide nano-catalyst under UV irradiation. J. Sol-Gel Sci. Technol. 2006, 40, 31-38. [CrossRef]

12. Agafonov, V.V.; Vinogradov, A.V. A new approach to apply crystalline titania hydrosols onto a polyester cloth. Mendeleev Commun. 2013, 23, 286-288. [CrossRef]

13. Bozzi, A.; Yuranova, T.; Kiwi, J. Self-cleaning of wool-polyamide and polyester textiles by $\mathrm{TiO}_{2}-\mathrm{rutile}$ modification under daylight irradiation at ambient temperature. J. Photochem. Photobiol. A 2005, 172, 27-34. [CrossRef]

14. Yuranova, T.; Laub, D.; Kiwi, J. Synthesis, activity and characterization of textiles showing self-cleaning activity under daylight irradiation. Catal. Today 2007, 122, 109-117. [CrossRef]

15. Galoppini, E. Linkers for anchoring sensitizers to semiconductor nanoparticles. Coord. Chem. Rev. 2004, 248, 1283-1297. [CrossRef]

16. Huang, K.; Yang, K.; Lin, S.; Lian, W. Antiwrinkle treatment of cotton fabric with a mixed sol of TEOS-TTB/DMDHEU. J. Appl. Polym. Sci. 2007, 106, 2559-2564. [CrossRef]

17. Galkina, O.L.; Vinogradov, V.V.; Vinogradov, V.V.; Agafonov, A.V. Development of the temperature sol-gel synthesis of TiO2 provide self-cleaning effect on the textile materials. Nanotechnol. Russ. 2012, 7, 604-614. [CrossRef]

18. Cerveau, G.; Corriu, R.J.P.; Lerouge, F.; Bellec, N.; Lorcy, D.; Nobili, M. Self-organization of a tetrasubstitutedtetrathiafulvalene in a silica based hybrid organic-inorganic material. Chem. Commun. 2004, 4, 396-397. [CrossRef]

19. Prorokova, N.P.; Kumeeva, T.Y.; Agafonov, A.V.; Ivanov, V.K. Modification of polyester fabrics with nanosized titanium dioxide to impart photoactivity. Inorg. Mater. Appl. Res. 2017, 8, 696-703. [CrossRef]

20. Prorokova, N.P.; Vavilova, S.Y. The modifying effect of ammonium nitrate and sodium hydroxide on poly(ethylene terephthalate) materials. Fiber Chem. 2004, 36, 413-415. [CrossRef]

21. Prorokova, N.P.; Chorev, A.V.; Vavilova, S.Y. Chemical method of surface activation of poly(ethylene terephthalate) fibre materials. Part 1 . Study of the modifying effect of sodium hydroxide solution and products made from quaternary ammonium salts. Fiber Chem. 2009, 41, 158-163. [CrossRef]

22. Kuzmin, S.M.; Prorokova, N.P.; Khorev, A.V. Chapter 19. Plasma-assisted modification of textile yarns in liquid environment. In Textiles: Types, Uses and Production Methoda; El Nemr, A., Ed.; Nova Science Publishers, Inc.: New York, NY, USA, 2012; pp. 557-578.

23. Prorokova, N.P.; Chorev, A.V.; Kuzmin, S.M.; Vavilova, S.Y.; Prorokov, V.N. Chemical Method of Fibrous Materials Surface Activation on the Basis of Polyethylene Terephthalate (PET). Chem. Chem. Technol. 2014, 8, 293-302. [CrossRef]

24. Prorokova, N.P.; Kumeeva, T.Y.; Kuz'min, S.M.; Kholodkov, I.V. Modification of polyester fibrous materials with surface barrier discharge for making them more hydrophilic. Russ. J. Appl. 2016, 89, 111-118. [CrossRef]

25. Prasad, G.K.; Agarwal, G.S.; Singh, B.; Rai, G.P.; Vijayaraghavan, R. Photocatalytic inactivation of Bacillus anthracis by titania nanomaterials. J. Hazard. Mater. 2009, 165, 506-510. [CrossRef]

26. Linsebigler, A.L.; Lu, G.; Yates, J.T., Jr. Photocatalysis on $\mathrm{TiO}_{2}$ Surfaces: Principles, Mechanisms, and Selected Results. Chem. Rev. 1995, 95, 735-758. [CrossRef]

27. Neri, G.; Rizzo, G.; Galvagno, S.; Loiacono, G.; Donato, A.; Musolino, M.G.; Pietropaolo, R.; Rombi, E. Sol-gel synthesis, characterization and catalytic properties of Fe-Ti mixed oxides. Appl. Catal. A Gen. 2004, 274, 243-251. [CrossRef]

28. Pal, B.; Hata, T.; Goto, K.; Nogami, S. Photocatalytic degradation of o-cresol sensitized by iron-titania binary photocatalysts. J. Mol. Catal. A Chem. 2001, 169, 147-155. [CrossRef]

29. Wang, C.-T.; Ro, S.-H. Nanoparticle iron-titanium oxide aerogels. Mater. Chem. Phys. 2007, 101, 41-48. [CrossRef] 
30. Lei, X.F.; Xue, X.X.; Yang, H. Preparation and characterization of Ag-doped $\mathrm{TiO}_{2}$ nanomaterials and their photocatalytic reduction of $\mathrm{Cr}(\mathrm{VI})$ under visible light. Appl. Surf. Sci. 2014, 321, 396-403. [CrossRef]

31. Sokmen, M.; Candan, F.; Sumer, Z. Disinfection of E. coli by the Ag- $\mathrm{TiO}_{2} / \mathrm{UV}$ system: Lipidperoxidation. Photochem. Photobiol. A Chem. 2001, 143, 241-244. [CrossRef]

32. Liu, Y.; Wang, X.L.; Yang, F.; Yang, X.R. Excellent antimicrobial properties of mesoporous anatase $\mathrm{TiO}_{2}$ and $\mathrm{Ag} / \mathrm{TiO}_{2}$ composite films. Micropor. Mesopor. Mater. 2008, 114, 431-439. [CrossRef]

33. Apphouse, P.; Varghese, A.; Tendero, C. Stable hydrosols for $\mathrm{TiO}_{2}$ coatings. J. Sol-Gel Sci. Technol. 2010, 56, 250-263. [CrossRef]

34. Prorokova, N.P.; Kumeeva, T.Y.; Gerasimova, T.V.; Agafonov, A.V. Effect of the structure of Fe-doped titania-based nanocomposites on the photocatalytic activity of polyester fabrics modified by them. Inorg. Mater. 2017, 53, 1336-1342. [CrossRef]

35. Agafonov, A.V.; Vinogradov, A.V. Sol-gel synthesis, preparation and characterization of photoactive $\mathrm{TiO}_{2}$ with ultrasound treatment. J. Sol-Gel Sci. Technol. 2009, 49, 180-185. [CrossRef]

36. Khalyavka, T.A.; Shimanovskaya, V.V.; Strelko, V.V.; Kapinus, E.I. Photocatalytic activity of titanium dioxide in the degradation of methylene blue and tetrachlorofluorescein in aqueous solutions. Theor. Exp. Chem. 2001, 37, 58-62. [CrossRef]

37. Prorokova, N.P.; Kumeeva, T.Y.; Novikov, V.V.; Holodkov, I.V. Regulation of the tribological characteristics of polyester fabrics by surface modification using tetrafluoroethylene telomeres. J. Frict. Wear 2018, 39, 121-128. [CrossRef]

38. ASTM E2149-10 Standard Test Method for Determining the Antimicrobial Activity of Immobilized Antimicrobial Agents under Dynamic Contact Conditions; ASTM International: West Conshohochen, PA, USA, 2001.

39. Bui, T.H.; Felix, C.; Pigeot-Remy, S.; Herrmann, J.M.; Lejeune, P.; Guillard, C. Photocatalytic inactivation of wild and hyper-adherent Escherichia coli strains in presence of suspended or supported $\mathrm{TiO}_{2}$ : Influence of the Isoelectric point of the particle size and of the adsorptive properties of titania. J. Adv. Oxid. Technol. 2008, 11, 510-518. [CrossRef]

40. Nadtochenko, V.A.; Radtsig, M.A.; Khmel, I.A. Antimicrobial effect of metallic and semiconductor nanoparticles. Nanotechnol. Russ. 2010, 5, 277-289. [CrossRef]

41. Zolotavin, P.; Permenova, E.; Sarkisov, O.; Nadtochenko, V.; Azouani, R.; Portes, P.; Chhor, K.; Kanaev, A. Two-photon luminescence enhancement of silver nanoclusters photodeposited onto mesoporous $\mathrm{TiO}_{2}$ film. Chem. Phys. Lett. 2008, 457, 342-346. [CrossRef]

42. Zhang, H.J.; Chen, G.H. Potent antibacterial activities of $\mathrm{Ag} / \mathrm{TiO}_{2}$ nanocomposite powders synthesized by a one-pot sol-gel method. Environ. Sci. Technol. 2009, 43, 2905-2910. [CrossRef] [PubMed]

43. Prorokova, N.P.; Kumeeva, T.Y.; Kuznetsov, O.Y. Antimicrobial properties of polyester fabric modified by nanosized titanium dioxide. Inorg. Mater. Appl. Res. 2018, 9, 250-256. [CrossRef]

44. Wang, R.; Wang, Y. Characterization of titania hydrosol and its influence on light fastness of polyester fabric. Procedia Eng. 2011, 18, 307-311. [CrossRef]

45. Selishev, D.S.; Karaseva, I.P.; Uvaev, V.V.; Kozlov, D.V.; Parmon, V.N. Effect of preparation method of functionalized textile materials on their photocatalytic activity and stability under UV irradiation. Chem. Eng. J. 2013, 224, 114-120. [CrossRef]

(C) 2020 by the authors. Licensee MDPI, Basel, Switzerland. This article is an open access article distributed under the terms and conditions of the Creative Commons Attribution (CC BY) license (http://creativecommons.org/licenses/by/4.0/). 